\title{
CFD analysis of Gypsum crystallization fouling in 2D plate heat exchangers
}

\author{
Amit Kumar ${ }^{1 *}$, Sandeep Yadav², Dilbag Singh Mondloe ${ }^{3}$, Vinayak Barewar ${ }^{1}$, Yogender Kumar ${ }^{1}$ \\ and Vinay Pandit ${ }^{1}$ \\ Assistant Professor, Department of Mechanical Engineering, Indira Gandhi Engineering College, Sagar, MP, India ${ }^{1}$ \\ Assistant Professor, Department of Mechanical Engineering, MBM Engineering College, JNV University, Jodhpur, \\ Rajasthan, India ${ }^{2}$ \\ Assistant Professor, Department of Mechanical Engineering, Government Engineering College, Jagadalpur, India ${ }^{3}$
}

Received: 16-August-2021; Revised: 24-January-2022; Accepted: 26-January-2022

(C2022 Amit Kumar et al. This is an open access article distributed under the Creative Commons Attribution (CC BY) License, which permits unrestricted use, distribution, and reproduction in any medium, provided the original work is properly cited.

\begin{abstract}
The deposition of material present in the flowing fluids onto the surfaces of various internal parts of heat exchangers is the main reason for thermal efficiency reduction. This phenomenon of deposition is known as fouling. The fouling phenomenon could be understood prominently by experimental and numerical investigations. In the current work, computational fluid dynamics (CFD) has been used to develop numerical models to simulate the crystallization fouling, and a correlation of an optimum operating conditions for minimum fouling effect has been achieved. The development of numerical models required many stages, and these stages involved a critical evaluation of all the processes in crystallization fouling. In the first stage, the numerical solutions for the crystallization flux are validated with corresponding experimental fouling resistance distributions. The validation provides an insight into factors determining the likelihood of the fouling mechanisms. Then, the impact of deposit growth on fouling is determined by calculating the fouling resistance and monitoring its temporal variation. Afterward, the numerical values of the fouling rate are calculated from the resulting fouling curves. The simulation results show that fouling includes both time and space dependency. Also, the fouling thickness increases up to $1.4 \mathrm{~mm}$ in approximately 200hrs time passage for a given heat flux of $54 \mathrm{~kW} / \mathrm{m}^{2}$ and concentration of $2.42 \mathrm{~g} / \mathrm{l}$ at different inlet velocities. Similarly, the fouling resistance increases up to $0.003 \mathrm{~K} . \mathrm{m}^{2} / \mathrm{W}$ under the same operating conditions. Almost the same trends have been obtained at the same inlet velocity of $0.2 \mathrm{~m} / \mathrm{s}$ and different heat transfer rates. In the context of space dependencies of fouling phenomenon, the mass deposition rate of fouling increases from $0.005 \mathrm{gm} / \mathrm{m}^{2}$ s to $0.035 \mathrm{gm} / \mathrm{m}^{2}$ s along the length of the plate from $380 \mathrm{~mm}$ to 600 $m m$ at a given heat flux of $54 \mathrm{~kW} / \mathrm{m}^{2}$ and concentration of $2.42 \mathrm{~g} / \mathrm{l}$ at different inlet velocity. And, hence the correlation of an optimum operating condition of minimum fouling effect was achieved for a two dimensional (2D) plate heat exchanger. The results obtained from the CFD simulation indicate that multiple factors affect the fouling phenomenon including fouling thickness, fouling resistance, heat transfer coefficient, velocity, heat flux input, and so on at the local level. Further, the fouling phenomenon of heat exchangers has been accessed with the help of various related innovative ideas of modeling in CFD. The research objectives of predicting the fouling behavior using CFD simulation have been achieved, and various exciting results have been found.
\end{abstract}

\section{Keywords}

Computational fluid dynamics, Crystallization fouling, Plate heat exchanger.

\section{Introduction}

The most common equipment used in processes industries are heat exchangers. These devices are used for exchanging heat between two process fluid streams. The heat exchanger is an essential modern tool in the process industry. The objectives of heat exchangers in the process industries are to meet boiling, condensation, bulk heating, and cooling or evaporation requirements.

*Author for correspondence
Heat exchangers' performance and efficiency can be measured by measuring the amount of heat transferred using the minimum area of heat transfer and the pressure drop. The main problem faced during the working of heat exchangers is fouling, which results in their poor efficiency. Fouling is the deposition and buildup of undesired elements in process fluids, such as scale, suspended particles, insoluble salts, and so on, on the interior or external surfaces of processing equipment such as boilers and heat exchangers. The most significant consequence of fouling is the reduction in the thermal efficiency of a 
processing unit. For the heat exchanger, this means obtaining an outlet stream at a temperature different from that calculated when the unit was designed. The entire process seems to be affected if the design specifications are not achieved.

The fouling mechanisms in heat transfer processes have been studied and attempts have been made to implement a generalized predictive method to overcome the fouling problem in heat exchangers [1]. The article can be seen as the beginning of a continuous research period into a phenomenon considered a complex science. According to Mukherjee in [2], fouling is the unavoidable consequence of heat transfer between two flowing streams across the metal surface, known as heat transfer surface. An experimental investigation is far more accurate than numerical simulations, but they are somewhat rigid in geometrical designs. They generally require expensive flow visualization technologies like particle image velocimetry (PIV) to study fluid dynamics completely. However, Numerical investigation techniques like computational fluid dynamic (CFD) offer flexibility in geometrical designs, and flow visualization is also very cheap and easy to accomplish. But, the accuracy of computational results should be first validated against analytical or experimental data. An important motivation for the current research is the ability to describe the process through numerical modeling adequately. However in [3], Karabelas has noted that despite lengthy experimental investigations, the prediction capability is unsatisfactory and that there exists a difficulty in developing models to predict the temporal variation in the fouling resistance. This motivates the development of alternate methods to predict the fouling phenomenon. Before developing an alternate fouling model, the key processes involved in fouling need to be understood, and those existing models need to be assessed. In the present work, CFD simulation of the fouling phenomenon is carried out to understand the physics of fouling formation and its effects on heat exchangers performance and experimental data for validation is collected from [4].

The objective of the present study is to develop a model using CFD that would detail the fouling common to crystalline streams. Once completed, the model would assist in furthering the understanding of fouling and the intricate interactions of key operation of parameters on a local scale. Model components were developed and assessed using a progressive stage-wise strategy.

\subsection{Crystallization fouling}

Crystallization is considered the most dominant deposition mechanism, which mainly occurs in desalination plants. Whenever the concentrations are extremely high, the solubility of most of the salts increases with an increase in temperature. But it involves the exceptions like, with an increase in temperature, there is a decrement in the solubility of some salts, as observed in the study conducted by Khan et al. [5]. These salts are responsible for depositing scales in process equipment, which is very often used in different industries. The responsible dissolved factors are mainly calcium sulfate $\left(\mathrm{CaSO}_{4}\right)$ and calcium carbonate $\left(\mathrm{CaCO}_{3}\right) \cdot \mathrm{CaSO}_{4}$ has many variants also, e.g., anhydrite, gypsum, or hemihydrates. In the study on calcium-based salts, while in, Langelier et al. [6] found that $\mathrm{Ph}$ value controls scale formation based on $\mathrm{CaCO}_{3}$, e.g., slightly higher $\mathrm{Ph}$ value shows lesser scale formation. But there is no impact of $\mathrm{Ph}$ value on CaSO4-based deposits. For example, if seawater is evaporated of its 2/3rd quantity at a maintained temperature of $100^{\circ} \mathrm{C}$, seawater becomes saturated for anhydrite-based $\mathrm{CaSO}_{4}$. Therefore, prediction of the tendency of water to deposits scale is critical. It is directly correlated with the concentration of salts or mixture of salts at operating temperature. Many researchers focused study on the rate of crystallization. They quoted that supersaturation is the driving force for scale formation. Therefore, an initial understanding of saturation concentration is essential to forecast deposition rates on exposed surfaces. The effect of providing vortex generators (VGs) of different shapes in a rectangular channel has been investigated in [7]. It has also been found that the turbulence generated due to VGs significantly impacts the $\mathrm{CaSO}_{4}$ crystallization fouling deposition. They used three VGs of half-cylinder, rectangle, and triangle shapes in the rectangular channel. Their numerical simulation study on ANSYS fluent 14.0 found that with all three VGs, the fouling resistance shows the same trend to various operating parameters like velocity, concentration, wall temperature, etc. They also concluded that the fouling resistance of the triangle VG is the smallest without considering the flow resistance.

1.1.1Mechanisms involved in crystallization fouling

Formations of crystalline fouling involve three-stage mechanisms, namely supersaturation, crystal nucleation, and crystal growth. Supersaturation is the precondition in a solution responsible for substances to be crystallized. Lv et al. in [8] demonstrated the crystallization in the supersaturated zone and found that crystallization of substances in the solutions 
mainly occurs when the solutions with normal solubility [9] are cooled continuously, or solutions with inverse solubility are heated or vice versa. Bornstein in [10] explained the mechanism of the formation of fouling due to crystallization. In which crystal nucleation is the first stage of the creation of crystals. It can be induced by adding particles or purely formulated in the solutions themselves. Crystallization fouling is more likely to be influenced by the former than the latter. Crystal growth is the last step in the crystallization process, and it involves multiple complex mechanisms. Surface energy effect, adsorption layer, and diffusion are at least three key mechanisms involved.

\section{$1.2 \mathrm{CaSO}_{4}$ solubility in water}

Bott in [11] has conducted experiments to judge the impact of temperature on $\mathrm{CaSO}_{4}$ solubility. For ordinary solid phases under the operating condition of temperature more than $40^{\circ} \mathrm{C}$, they found that solubility of $\mathrm{CaSO}_{4}$ decreases with an increase in temperature. It has also been concluded that the locations next to the heat transfer surface have the highest warmth at normal operating conditions and therefore these locations are the perfect sites for the growth of scales. Further, it has been discovered that the temperature dependence of $\mathrm{CaSO}_{4}$ solubility in water is responsible for its precipitation and hence fouling [12]. Furthermore, Mullin found that water evaporation, mixing of various solutions or even the same solution in a saturated condition at different temperatures, and so on, are the other alternatives to achieve supersaturation apart from heating or cooling the solution.

The present research article has been written with different sections. In which, the first section introduces an overview of the mechanism of crystallization fouling and the mechanism involved for the same, while in section 2 findings from the literature are discussed. Methods including CFD modeling, computational domain and procedure are described in section 3 . In the section 4 , results and the important findings from the results are discussed. This section ends up with the limitations of the present study. Conclusions and the future scope of the present work are discussed in the last section of the paper.

\section{Literature survey}

The crystal growth rate may be equated as the difference between supersaturated and equilibrium saturated concentrations as observed by Mullin in
[12] and mathematically can be represented with the help of Equation 1;

$\emptyset_{D}=\beta\left(C_{b}-C_{s}\right)$

Where $\emptyset_{D}$ the mass of solid deposited per unit is time,

$C_{b}$ is bulk concentration at the face of growing crystals, and $C_{s}$ is equilibrium saturation concentration on the surface of growing crystals, $\beta$ is mass transfer coefficient. Scaling in steam boilers and evaporators is prevalent due to several types of crystallization fouling other than normal salt precipitation. These machines are generally run at high temperatures, which can cause bubbles. These bubbles on the rough heat transfer surface may operate on a supersaturation zone for nuclei and as contact regions for particles to precipitate.

According to the phenomena of wax deposition from kerosene, crystals may be formed initially if the subcooled surface has a temperature lower than the 'cloud point' of such hydrocarbons. The deposition phenomenon can be seen as equivalent fouling resistance offered by deposited wax, as represented in Equation 2.

$R_{f}=\frac{1}{U}-\frac{1}{U_{o}}=\frac{T_{w}-T_{w o}}{\dot{q}}$

Where $R_{f}$ is fouling resistance, $U_{o}$ is the overall heat transfer coefficient at a time (t) equal to zero, whereas $U$ is the overall heat transfer at any time after deposition (present time). $T_{w o}$ is wall temperature at the time $(\mathrm{t})$ equals zero, $T_{w}$ is wall temperature at present time, $\dot{q}$ is heat flux. Equation 2 is the relation between thermal fouling resistance and wall temperature. The timing is considered time zero under clean conditions and present time, after operating a specific heat-exchanger or after wax deposition.

However, it is almost impossible to evaluate unknown fouling resistance due to the difficulty in obtaining wall temperatures. Therefore, a general mathematical model of fouling phenomena was suggested in [8] (Equation 3).

$\frac{d x_{f}}{d t}=K_{1} \grave{c} \dot{m}-K_{2} \tau x_{f t}$

Where $K_{1}$ and $K_{2}$ are fixed constants; $\dot{m}$ is mass flow per unit time; $\grave{c}$ is the concentration of deposits; $x_{f t}$ is the thickness of deposits at present time; $\tau$ is shear stress. Many scientists have developed the fouling model due to the two competing terms: deposition rate and removal rate. Because crystallization fouling is a regular occurrence for the substances mentioned 
above, the mathematical model for this fouling has been investigated and developed for a long time. Because the mechanisms of material adhesion to the crystal lattice are complicated, crystallization fouling is often seen as a mechanism similar to a chemical reaction [6].

The work carried out by Kern [8] can be used as a foundation for the further development of a precipitation fouling model. The fouling resistance calculation has been stated [13] as (Equation 4):

$\frac{d R_{f}}{d t}=\left(\frac{\dot{m}}{\rho \lambda}\right)$ scale

Where $\dot{m}_{\text {scale }}$ as scaling mass flux, $\rho_{\text {scale }}$ as scaling density, $\lambda_{\text {scale }}$ as thermal conductivity. Moreover, Watkinson and Wilson in [14] experimented to understand fouling behavior. They found that the $(\rho \lambda)$ scale was about $5000 \mathrm{gWm}^{-4}$. The Hasson model detachment term has been waived off due to complexity and difficulty in capturing the process in [15].

While Bohnet in [16] checked the influence of mass diffusion controlling and surface reaction controlling on crystallization fouling. These models are as shown with the following equations, where mass diffusion controlling and surface reaction controlling can be represented by Equation 5 and Equation 6 respectively.

$\frac{d m_{f}}{d t}=\beta\left(C_{b}-C_{s}\right)$

Where $\quad C_{b}$ is bulk concentration, $C_{f}$ is vicinity concentration of fouling layer, $C_{s}$ is the concentration at saturation level.

It can be observed that salt precipitation, particularly $\mathrm{CaCO}_{3}$ a prevalent scale in cooling water, has a significant impact on fouling-model development. Following that, several other investigations focused on the same salt solutions and utilized models to identify fouling behavior [17].

Al-ahmad and Aleem [18] have used a basic asymptotic fouling model equations to forecast fouling in one of Saudi Arabia's desalination plants and compared the results to the data set of actual fouling. The correlation coefficient between the two data was higher than $90 \%$, according to the results. Experiments have been carried out with investigating $\mathrm{CaSO}_{4}$.
Ma et al. [19] has suggested the semi-empirical correlation model. Their model was highly comparable to the results obtained in [7] in terms of originality.

Further, Isogain et al. [20] have proposed a model without using the salt-based solution to predict organic crystallization fouling in plant crystallizer units.

The fouling model is the addition of the Reitzer model [21] as formation term and model [7] as the removal term, which was proposed by Inokuchi et al. [22] for the same problem.

$\mathrm{Xu}$ et al. [7] have emphasized that Equation has the basic assumption of linearity in temperature variation-based solubility and that the Reitzer model [21] has a single order. It can be written as Equation 6.

$\frac{d R_{f}}{d t}=k_{2}\left(\frac{\dot{q}}{h}\right)-k_{3} \tau x_{f}$

Where $R_{f}$ is fouling resistance, $k_{2}$ and $k_{3}$ are constants, $\dot{q}$ is heat flux, $\mathrm{h}$ is heat transfer coefficient, $\tau$ is shear stress, and $x_{f}$ as deposit thickness.

The crystallization fouling process was primarily regulated by surface integration, as discovered by Pääkkönen et al. [23, 24], and crystallization-based fouling is affected by the resident time associated with wall boundary. This residence time is also the function of friction velocity.

Further, Epstein [25] has added a time scale factor $\left(t_{\mathrm{sf}}\right)$ in the calculation in their model for fouling formation.

Similarly, in Pääkkönen et al. [26] have used time for proteins [25] and $\mathrm{CaSO}_{4}$ solutions. Finally, Pääkkönen et al. [26] introduced the CFD model, the perfect blend of various affecting factors such as integral surface term, shear stress-based residence time, fluid hydrodynamics, and heat transaction with the fouling model. Recently some new techniques are being used by different researchers for fouling analysis with numerical modeling.

Nikoo et al. [27] used extended Derjaguin, Landau, Verwey, and Overbeek (DLVO) theory to predict the $\mathrm{CaSO}_{4}$ fouling propensity and compared the results obtained from this technique with experimental data in their investigation, and found $75 \%$ of all data consistent with the proposed fouling propensity 
indicator (FPI) criterion.

Sundar et al. [28] developed a generalized and scalable model for accurately predicting fouling resistance based on deep learning for cross-flow heat exchangers. The heat exchangers' fouling and heat transfer physics have been demonstrated through a neural network framework. They found an adequately trained model of the proposed fouling resistance prediction module can be deployed to make real-time predictions in the industrial setting. The properties of the fouling process from $\mathrm{CaSO}_{4}$ solutions to the heat transfer surface with and without bulk precipitation have been studied experimentally in [29]. The effects of the rotational bulk solution, Reynolds number (Re), and surface temperature $\left(\mathrm{T}_{\mathrm{s}}\right)$ on fouling mechanism, behavior, and rate are examined. In the absence of bulk precipitation, fouling can improve total heat transmission. Surface crystallization reduces fouling resistance rate with increasing Re but has little effect above 80000 Re.

$\mathrm{Xu}$ at al. [30] found that plate heat exchangers are commonly utilized in industrial processes. They also found that the concentration and flow velocity affect the plate heat exchanger fouling characteristics. The deposition mass rate, removal mass rate, and asymptotic value of fouling resistance all rise with $\mathrm{CaSO}_{4}$ concentration and hot fluid input temperature, but decrease with the inlet flow velocity. The effect of cold fluid inlet temperature may be insignificant.

Schlüter et al. [31] has concluded that an areaaveraged heat transfer evaluation and an integral heat balance are used to calculate integral thermal fouling resistance. Contrarily, existing models overlook local variations that can alter integral fluid dynamics. To forecast and link- the local and integral fouling resistances, thermal and mass-based approaches and to determine surface roughness or constrictions, the acquired local thermal fouling resistances are recalculated using mass-based parameters.

From the literature survey, it has been found that crystallization fouling occurs in stages. It starts with the initiation of a crystal called nuclei, in the bulk of liquid followed by crystal growth and finally its attachment with a solid surface in contact. The attachment or deposition of crystal resulted from two competing terms named deposition rate and removal rate. Further, as the mechanisms of material adhesion to the crystal lattice are complicated, the crystallization fouling mechanism proceeds like a chemical reaction procedure.
Moreover, various concepts were presented by different researchers to model the crystallization fouling due to different types of salts present in the working fluids. Also, many experimental and simulation analyses have already been presented for crystallization fouling and its governing factors but till now only a few factors like concentration, temperature, and in some cases inlet velocity were investigated. The effect of the geometry of the passage on fouling has also been considered by some authors in their analysis recently. Additionally, some new techniques of analysis like the DLVO method, deep learning have already been used by some authors. But till now, detailed investigation of operating parameters on crystallization fouling has not been carried out sufficiently. So, there is a need to analyze the same through experimental or numerical analysis. In the present study crystallization fouling analysis including its dependencies on various governing parameters has been carried out using CFD. The results obtained properly justify the proposed approach.

\section{Methods}

The methods include CFD modeling, computational domain and computational procedure as described in the following subsections:

\subsection{0verview of CFD modelling}

The complete working mechanism of the present work has been presented with the help of the block diagram as shown in Figure 1:

The main objective of CFD is to model the continuous fluid flows with partial differential equations (PDEs). The PDEs are discretized into the algebraic equations and later solved numerically. Thus the results are validated, and simulation-based design is achieved using the 'build \& test' technique. The simulation of physical fluid phenomena can also be predicted by using CFD modeling very quickly compared to experimental modeling. The steps by step process of CFD modelling is shown in Figure 2

In this study, ANSYS fluent 6.3 is used to describe the flow regime and heat and mass transfer processes in a 2D plate heat exchanger during the crystallization fouling process (by considering fouling on some parts of the plate, where it is being heated with a constant heat flux). 


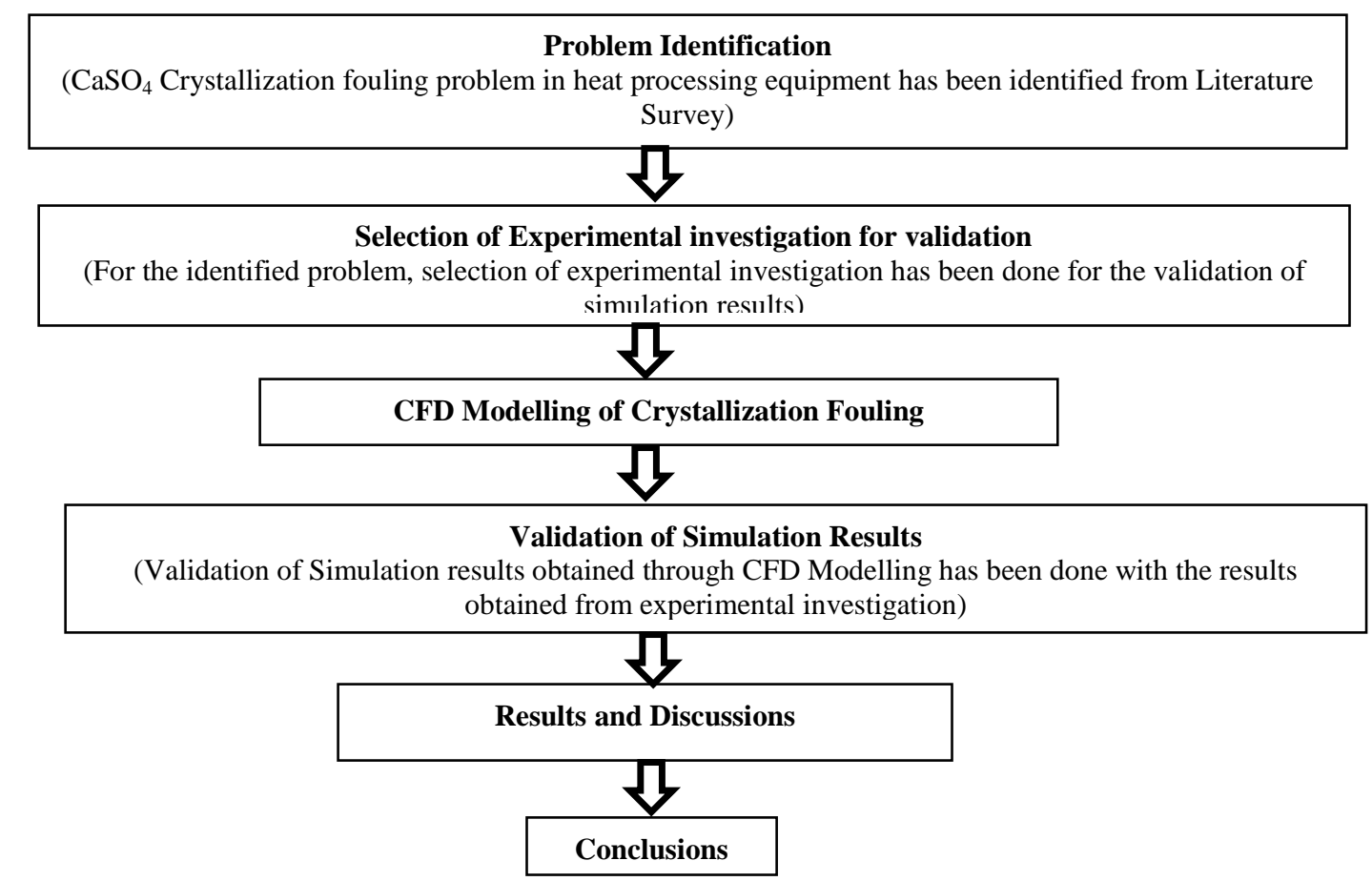

Figure 1 Block diagram for the proposed work

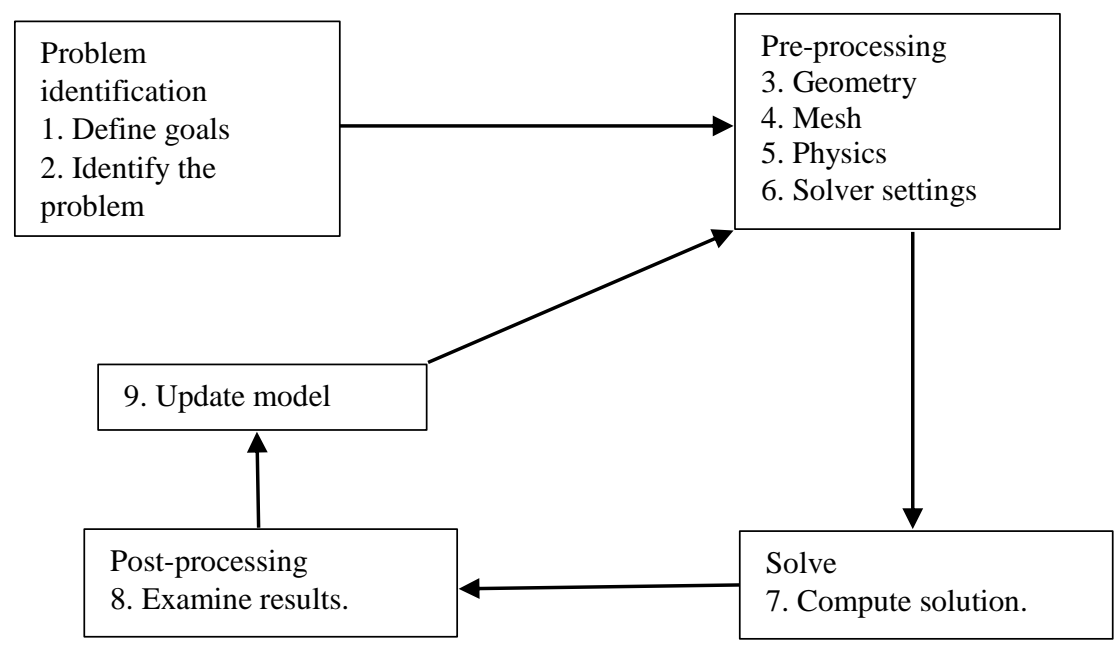

Figure 2 Flow chart of computational fluid dynamics

\subsubsection{Governing equations}

For flows involving heat transfer, fluent solves mass, momentum, and energy conservation equations. The species conservation equation can be solved for flows, including species mixing or reactions.

\section{Transport equation}

The corresponding general transport equation for incompressible laminar flow is shown by the Equation 7. $\frac{d \rho \varnothing}{d t}+\mathrm{U} \cdot \nabla(\rho \varnothing)=\nabla \cdot \Gamma_{\varnothing} \nabla+S_{\varnothing}$

The variable of the equation is referred to as the general transport property $(\varphi)$. Here $\rho$ is the density, $\mathrm{U}$ is the velocity, $\Gamma_{\varnothing}$ is the diffusion coefficient, $S_{\varnothing}$ is the source term that accounts for any sources or sinks that either create or destroy $\varnothing$. It represents the transport variables like velocity, temperature, and mass fraction. These equations are solved numerically using the finite volume or control volume technique. 


\section{Turbulence models}

Equation 7 represents the laminar form of the transport equation. Evaluating the turbulent form of Equation 7 requires performing a step known as time averaging. Essentially, it involves breaking down the velocity into two components. One represents the mean value, and the other represents the fluctuations that are characteristic of turbulent flow. Equation 8 is the result of this transformation.

Where $\rho$ is the density, $U$ is the velocity, $\mu$ is the viscosity, $\mathrm{p}$ is the pressure of the fluid and $\bar{u}^{\prime}$ is the fluctuating component of the velocity The main difference between the laminar form of the velocity equation and its turbulent form is the appearance of the second term on the right-hand side of the Equation 8. This term is representative of the turbulent stresses and is referred to as the Reynolds Stresses. These are additional to the viscous stresses, which are prominent within the boundary layer and appear in the laminar form of the equation. For the three-dimensional form of the equations, the Reynolds Stresses creates six extra unknowns, making the equations difficult to solve directly as the number of unknowns outnumber the number of equations. These additional unknowns are evaluated based on a theory developed by Boussinesq in the year 1877. For incompressible flow, one recalls Newton's law of viscosity, which states that viscous stress is proportional to the deformation rate (Equation 8):

$\frac{d \rho U}{d x}+\mathrm{U} \cdot \nabla(\rho \mathrm{U})=\nabla \cdot\left[\mu\left(\nabla \mathrm{U}+(\nabla U)^{T}\right)\right]+\nabla \cdot\left(\rho \overline{u^{\prime} u^{\prime}}\right)-$ $\nabla p$

$\tau_{i j}=\mu e_{i j}=\mu\left(\frac{d u_{i}}{d x_{j}}+\frac{d u_{j}}{d x_{i}}\right)$

Where, $\mu$ is the viscosity, $u_{i}$ and $u_{j}$ are the velocity components in $\mathrm{x}$ and $\mathrm{y}$ direction respectively.

Boussinesq developed an analogy for the Reynolds stress stating that the Reynolds stress was also related to the deformation rate but utilized a value of the turbulent viscosity as the proportionality constant (Equation 10):

$\tau_{i j}=-\rho \overline{u_{\imath}^{\prime} u_{j}^{\prime}}=\mu_{t}\left(\frac{d u_{i}}{d x_{j}}+\frac{d u_{j}}{d x_{i}}\right)$

Where $\tau_{i j}$ is the Reynolds stress, $\mu_{\mathrm{t}}$ is the viscosity at any time $t, u_{i}$ and $u_{j}$ are the velocity components in $x$ and $y$ direction respectively. Using this relationship, the values of the Reynolds Stresses can be approximated and, hence, solved for the turbulent equations for motion. An analogy of Equation 10 can be applied to the general case in the form of the eddy diffusivity hypothesis as shown in Equation 11.

$-\rho \overline{u^{\prime} \emptyset^{\prime}}=\Gamma_{t} \nabla \varnothing=\frac{\mu_{t}}{\sigma_{t}} \nabla \emptyset$

Where $\rho$ is the density, $\mu_{\mathrm{t}}$ is the viscosity at any time $\mathrm{t}, \sigma_{t}$ is the surface tension of the fluid at any time $\mathrm{t}$. The task now becomes deriving expressions to calculate the turbulent viscosity, which appears in Equation 10 and equation 11. Hence, completing the description of the Reynolds shear stresses requires defining the turbulent viscosity. The $\mathrm{k}-\varepsilon$ model (turbulent model) provides an algebraic definition to the turbulent viscosity and brings closure to the turbulent form of the transport equations. The low Re $\mathrm{k}-\varepsilon$ model and the standard k- $\varepsilon$ model, which uses scalable wall functions, are two forms of the models that have been used in this research.

\section{Energy transport equation}

One of the scalars to be modeled is temperature, which when substituted into the general transport equation forms the following turbulent energy transport Equation 12:

$\frac{d \rho_{s o l} C_{p} T}{d x}+\mathrm{U} . \nabla\left(\rho_{\text {sol }} C_{p} T\right)=\nabla .(\mathrm{k} \nabla \mathrm{T})+\nabla .\left(C_{p} \frac{\mu_{t}}{P r_{t}} \nabla \mathrm{T}\right)$

Where $\rho_{\text {sol }}$ the density of the solution is, $C_{p}$ is the specific heat at constant pressure, $\mathrm{T}$ is the temperature at any given time, $\mathrm{k}$ is the thermal conductivity of the fluid, $\mu_{t}$ and $P r_{t}$ are the viscosity and Prandtl number $\left(\mathrm{Pr}_{\mathrm{t}}\right)$ respectively at any time $t$. In Equation 12, the eddy diffusivity hypothesis (Equation 11) has been utilized to account for the turbulence characteristics of the flow. Hence, the last term of Equation 12 does not appear in the laminar version of the energy transport equation.

3.1.2Crystallization mechanism-eulerian modelling approach

Eulerian modelling approach to the homogeneous phase

This investigation is concerned with modeling the fouling mechanisms prominent in saline streams associated with the desalination industry. Several salts appear in the streams and are involved in fouling and the simplest is CaSO4. It is considered to be part of the equilibrium expressed in Equation 13.

$\mathrm{Ca}_{(a q)}^{2+}+\mathrm{SO}_{4(a q)}^{2-} \stackrel{k_{g}}{\rightarrow} \mathrm{Caso}_{4(s)}$

Equation 13 assumes that the two aqueous ions interact to form a $\mathrm{CaSO}_{4}$ precipitate. Above is a simplification as the $\mathrm{CaSO}_{4}$ can appear in a transitional aqueous form and a solid precipitate form. Sparingly soluble salts, like $\mathrm{CaCO}_{3}$ and 
calcium phosphate, have more complex chemistry and are also common fouling salts [26]. However, the simplicity of the $\mathrm{CaSO}_{4}$ as expressed in Equation 13, makes it most suitable for the present investigation. The primary goal of the investigation is to create models and carry out the analysis of the impact of operational parameters. More complicated chemistry can be applied once the foundations of the model have been produced.

The innovative part of this research is that the aqueous phase of Equation 13 is included in the CFD simulations as two additional transport equations, one for each species. The general transport equation (Equation 14) for the aqueous phase depicts the behavior of the mass fractions of the species $\left(\alpha_{c a}\right.$, $\left.\alpha_{\mathrm{SO}_{4}}\right)$.

$\frac{d \rho_{s o l} \alpha_{i}}{d x}+\operatorname{U.V}\left(\rho_{\text {sol }} \alpha_{i}\right)=\nabla \cdot\left(\rho_{s o l} D_{i} \nabla \alpha_{i}\right)+\nabla \cdot\left(\frac{\mu_{t}}{S c_{t}} \nabla \alpha_{i}\right)$ $+S_{\alpha_{i}}$

Equation 14 is the turbulent version and is for incompressible flow in which $\rho_{\text {sol }}$ is the density of the solution, $\alpha_{i}$ is the mass fraction of any of the species and $S_{\alpha_{i}}$ is the source term.

\section{Precipitation in bulk/boundary layer}

Depending on conditions, $\mathrm{CaSO}_{4}$ can be generated within the bulk/boundary layer through the precipitation reaction from the aqueous phase, as represented by Equation 13. Equation 15 represents a second-order reaction that is commonly associated with $\mathrm{CaSO}_{4}$ precipitation.

$r_{p p t}=k_{r}\left(\left[\mathrm{Ca}^{++}\right]\left[\mathrm{SO}_{4}^{--}\right]-\rho_{s o l} k_{s p}\right.$

Where, $k_{r}$ is the rate constant in association with Arrhenius relationship (Equation 16) and $k_{s p}$ is known as constant for solubility (Equation 17) in correlation with temperature as governing function.

$k_{r}=5.67 \times 10^{6} e^{\frac{6.49 \times 10^{4}}{R T}} \mathrm{~m}^{3} / \mathrm{moles}$

$\log k_{s p}=390.9619-\frac{12545.62}{T}-152.6264 \log \mathrm{T}+$ $0818493 \mathrm{~T}$

Equation 14 is utilized to model the precipitation in the CFD. The modeling is done by specifying an adjusted form of Equation 15 as the source term. The expression for the precipitation source term describing the consumption of both species of the aqueous phase follows Equation 18.

$S_{\alpha_{i}}=-k_{r}\left(\left[\frac{\rho_{\text {sol }^{\alpha}} \mathrm{Ca}^{2+}}{M W_{C a^{2+}}}\right]\left[\frac{\rho_{s o l^{\alpha}}{ }_{S O_{4}^{2-}}}{M W_{S O_{4}^{2-}}}\right]-k_{s p}\right)$
Equation 19 is the generalized equation for either the creation of particulate maters or the expenditure of ions in the solution as:

$$
\begin{aligned}
& S_{\alpha_{i}}=\mathrm{M} W_{\alpha_{i}} k_{r}\left(\left[\frac{\rho_{s o l}^{\alpha} \mathrm{Ca}^{2+}}{M W_{\alpha} \mathrm{Ca}^{2+}}\right]\left[\frac{\rho_{\text {sol }}^{\alpha}{ }_{S O_{4}^{2-}}}{M W_{\alpha_{S O_{4}^{2-}}}}\right] \quad-k_{s p}\left[\rho_{s o l}(1-\right.\right. \\
& \left(\alpha_{\mathrm{CaSO}_{4}}+\alpha_{\mathrm{Ca}^{2+}}+\alpha_{\mathrm{SO}_{4}^{2-}}\right)
\end{aligned}
$$

\section{Crystallisation fouling: precipitation at the surface}

Crystallization fouling results from the $\mathrm{CaSO}_{4}$ precipitation occurring at the surface (Equation 13). The formed precipitant adheres to the surface, forming a complex and tenacious crystal deposit. This process is incorporated into the CFD through a boundary condition imposed on the transport equations of the aqueous phases at the solid-liquid interface of interest. The crystallization fouling boundary conditions are formulated in a similar way to Equation 19 but are expressed as a flux $\left(\mathrm{J}_{\alpha}\right)$ per unit area and use a surface reaction rate constant $\left(\mathrm{k}_{\mathrm{R}}\right)$ :

$J_{i}=\mathrm{M} W_{\alpha_{i}} k_{r}\left(\left[\frac{\rho_{\text {sol }}{ }_{C a^{2+}}}{M W_{\alpha_{C a^{2+}}}}\right]_{\text {surf }}\left[\frac{\rho_{\text {sol }}{ }^{\alpha}{ }_{S O_{4}^{2-}}}{M W_{\alpha_{S O_{4}^{2-}}}}\right]_{\text {surf }}\right.$

$k_{s p}\left[\rho_{\text {sol }}\left(1-\left(\alpha_{\mathrm{CaSo}_{4}}+\alpha_{\mathrm{Ca}^{2+}}+\alpha_{\mathrm{SO}_{4}^{2-}}\right)\right]\right)$

Equation 20 includes a reaction rate constant and the solubility product (equation 17) for $\mathrm{CaSO}_{4}$ in a saline stream $\left(\mathrm{k}_{\mathrm{sp}}\right)$. Both depend on the local temperature (Equation 21).

$k_{r}=k_{r, 0} e^{-\frac{E_{A}}{R T_{\text {surf }}}}$

\subsection{Computational domain}

2D approach minimized significantly computational efforts for solving the problem for simulation of crystallization fouling in heat exchangers. Based on the flow velocity and surface average temperature distribution, the results of 2D model-based and 3D model-based simulations have been almost similar. The flow scenario was considered 2D due to the significant computational effort and expense of the 3D simulation in terms of computational time and memory.

Domain: The domain consists of a plate heat exchanger used in desalination plants. The aqueous solution of $\mathrm{CaSO} 4$ is the inlet to the heat exchanger, which is continuously heated by a constant heat flux through the plate. Solubility of $\mathrm{CaSO} 4$ decreases continuously with rising temperature, and it gets deposited as solid gypsum on the heated plate under the crystallization fouling mechanism as shown in Figure 3. 
Amit Kumar et al.

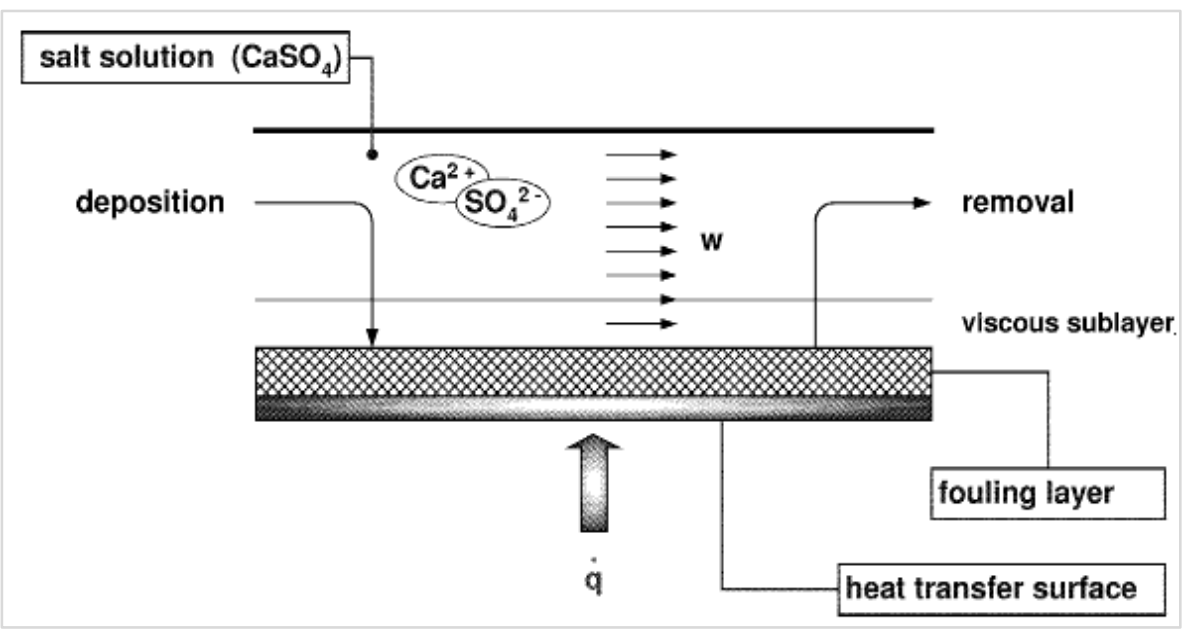

Figure 3 Flow chart of crystallization fouling processes on exposed heat transfer surfaces

Now the domain in $3 \mathrm{D}$ and $2 \mathrm{D}$ is represented by Figures 4 and Figure 5 respectively.

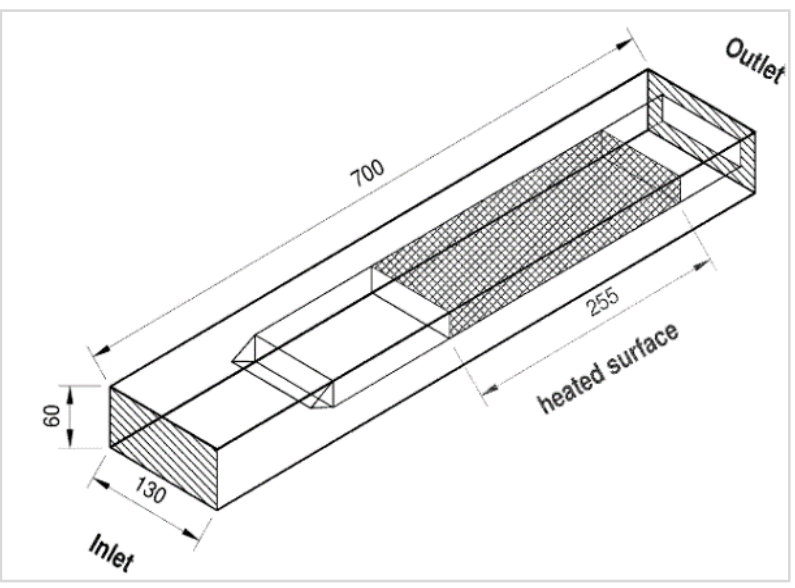

Figure 4 3D representation of the domain

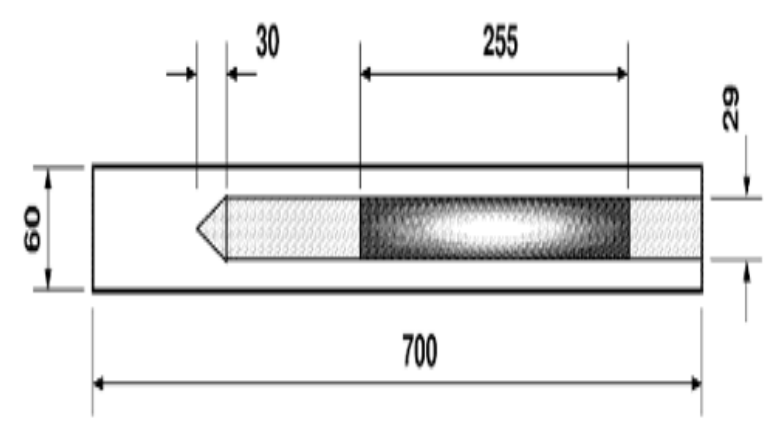

Figure 5 2D representation of the domain

Description of the above domain (Figure 4 and Figure 5) can be given as;
- The inlet is a rectangular cross-section with dimensions $130 \mathrm{~mm} \times 60 \mathrm{~mm}$.

- The outlet will be an annular space of rectangular shape with outer dimensions $130 \mathrm{~mm} \times 60 \mathrm{~mm}$ and inner dimensions $100 \mathrm{~mm} \times 29 \mathrm{~mm}$. Here the inner dimensions represent the cross-section of the plate.

- The plate with a length of $540 \mathrm{~mm}$ (extended from $140 \mathrm{~mm}$ distance from inlet to the end) divides the flow into two parts, above and below the plate.

The plate has a specified length of $255 \mathrm{~mm}$ that is to be heated with constant heat flux.

\section{Computational Grid:}

The grid used to perform the calculation is very important. Areas with large gradients require more grid points than the area with slight gradients. Grid points near the wall are made very fine as heat transfer near the border is very important to capture physics. With the use of a structured grid, the computing space was discretized. When it comes to channel and pipe flows, where significant changes in flow variables occur mostly orthogonal to the walls, the structured grid has two benefits over unstructured grid:

1. Structured grid having square cells is suitable for more reliable calculations and quicker convergence.

2. The structured grid supports aspect ratios of up to ten, equating to conserving grid cells and optimizing computing capacity. Such an aspect ratio causes significant cell distortion with an unstructured grid, resulting in simulation instability and errors.

For the simulation analysis carried out in the proposed work a quite fine grid was used in the wall 
boundary region of the domain. In the fine layer, the minimal mesh size has been $100 \mu \mathrm{m}$ in both directions was applied. Gambit 2.4 was used to create computing grids (provided by ANSYS Inc.). The grids obtained after meshing is shown in the Figure 6.
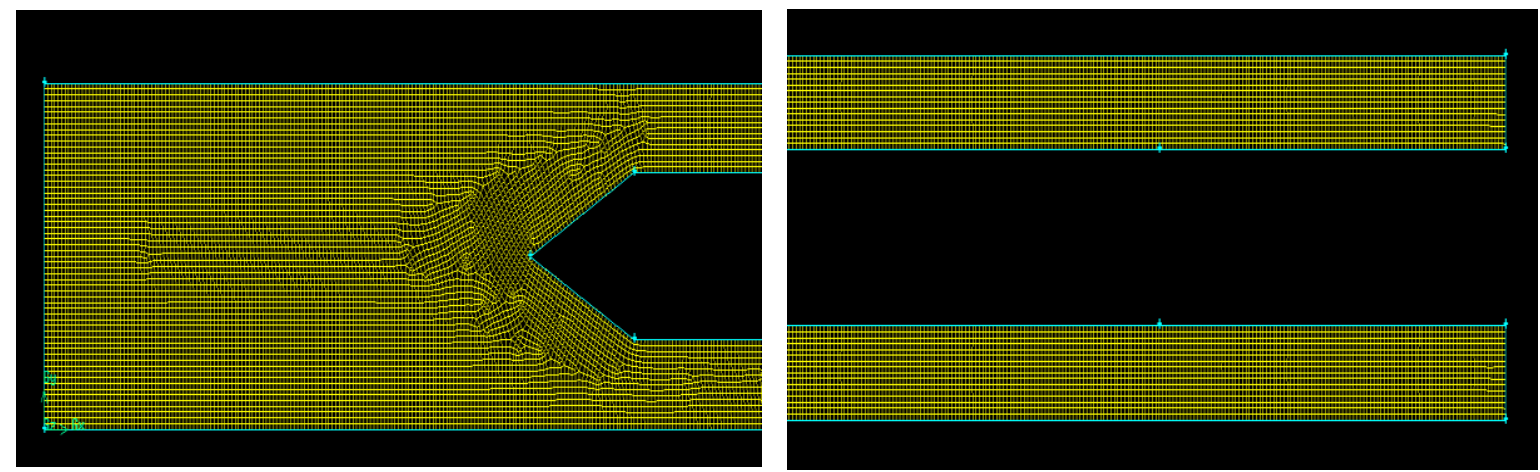

Figure 6 Grid used in the simulation of crystallization fouling mechanism (Computational grids used in actual is very fine then as seen in the grid here)

The number of grids, their shapes, nodes and other details are presented in Table 1

Table 1 Number of cells and nodes

\begin{tabular}{llll}
\hline Thickness(mm) & Length(mm) & $\begin{array}{l}\text { Number } \\
\text { of nodes }\end{array}$ & $\begin{array}{l}\text { Number of } \\
\text { quadrilaterals } \\
\text { (structured cells) }\end{array}$ \\
\hline 29 & 700 & 27835 & 26525 \\
\hline
\end{tabular}

\section{Boundary conditions:}

Different boundary conditions are presented in Figure 7:

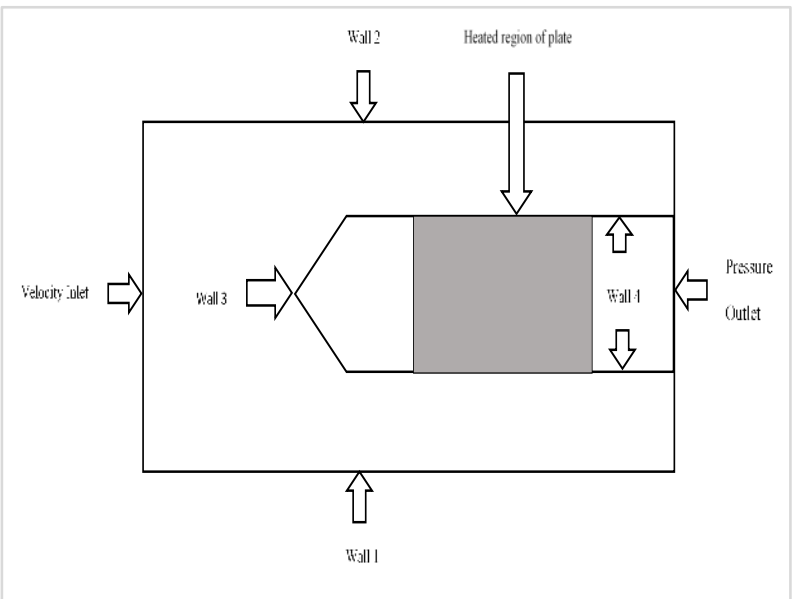

Figure 7 Different boundary conditions

1. The inlet of the domain was velocity type with the dimension of $60 \mathrm{~mm}$ depth. The aqueous $\mathrm{CaSO}_{4}$ solution has given an initial velocity (i.e., value of which depends upon the analysis case). The $\mathrm{CaSO}_{4}$ has provided an initial mass fraction in the water- calcium sulfate mixture. The temperature has been the room temperature as the solution prepared in a large tank at room conditions signifies a constant mass fraction of $\mathrm{CaSO}_{4}$ should be there at the inlet. Thus the boundary conditions are:

$\mathrm{v}_{\mathrm{i}}=$ depends upon analysis case, $\alpha_{\mathrm{CaSO}_{4}}=0.00242, \alpha_{\mathrm{H}_{2} \mathrm{o}}=0.99758, \mathrm{~T}=300 \mathrm{~K}$

2. The outlet has a type of pressure outlet with a cross-section area decreased to the thickness of the plate. As the outlet was at room conditions that signify it should be at atmospheric pressure.

$\mathrm{P}=\mathrm{P}_{\mathrm{atm}}$

3. No-slip condition at boundary has been used to ensure zero velocity components at wall 1 and wall 2 as per Prandtl theory of real fluid flow. It can be written as a boundary condition at the wall 1 and wall 2;

$\mathrm{V}=0, \mathrm{~T}=300 \mathrm{~K}$

4. A part of the dividing plate has given type wall, namely Wall-3 and Wall-4, which functions only as divider of the flow and has given no-slip condition such that temperature here also was same as outer walls $\mathrm{V}=0, \mathrm{~T}=300 \mathrm{~K}$

5. Another part of the plate is heated with a constant heat flux (i.e., depending on the analysis case). The constant heat flux was given with the help of electric heating of that portion of the plate; here, a no-slip condition is given such that plate temperature varies along the length. This plate has also been given as a site for the surface reaction, whose mechanism has been described separately in the mixture definition and model used. This reaction was responsible for the deposition of 
gypsum on it. $\dot{\mathrm{Q}}=$ depends upon analysis case, $\mathrm{V}$ $=0, T=$ depends upon heating.

\section{Thermo-chemical properties}

Fluent has many readily available thermochemical properties. These properties of fluid species have been utilized from the fluent database. Since fluid species correlate with temperature, their dependency has been executed in iterations to evaluate thermal and transport properties. The correlation is given below to calculate the property of single species and its mixtures;

For $T_{\min 1}<\mathrm{T}<T_{\max 1}: C_{p}(\mathrm{~T})=A_{1}+A_{2} \mathrm{~T}+$ $A_{3} T^{2}+\ldots \ldots$

For $T_{\min 2}<\mathrm{T}<T_{\max 2}: \quad C_{p}(\mathrm{~T})=B_{1}+B_{2} \mathrm{~T}+$ $B_{3} T^{2}+\ldots \ldots$

The range of coefficient $A_{i}$ and $B_{i}$ were given as default values in fluent. Specific heat capacity calculation is slightly different for composition-based mixtures, it follows the law of mixing as explained below;

Viscosity and thermal conductivity for the mixture were taken as mass-weighted mixing law. Mixture mass diffusivity was treated utilizing the multicomponent option and given diffusivity $=1.067 \mathrm{e}-5$. Density was defined using the volume-weighted mixing law.

\subsection{Computational procedure}

The simulation of mass, momentum, and energy equation (heat transfer) has been solved using fluent 6.3 by assuming nonlinear governing equations for every node. Real-time flow, e.g., the unsteady flow, has been employed because of the dynamic nature of the problem. Discretization of these nonlinear governing equations has been executed using an upwind scheme. An implicit method consisting double-precision segregated solver ensured the advancement of the solution. Since fouling is a surface-based problem, that is easily solved by defining the reaction mechanism. The reaction mechanism has defined by the definition of the mixture, in which gypsum is defined as depositing material. Table 2 illustrates the settings adopted for different models used for the simulation.

Table 2 Model formulation and selection

\begin{tabular}{ll}
\hline Model & Setting \\
\hline Space & 2D \\
\hline Time & Unsteady \\
\hline Type & Pressure-Based \\
\hline
\end{tabular}

\begin{tabular}{|c|c|}
\hline Model & Setting \\
\hline Gravity & Neglected \\
\hline Viscous & $\begin{array}{l}\text { Re-Normalisation Group (RNG) } \mathrm{k}-\varepsilon \text {, } \\
\text { with standard wall function }\end{array}$ \\
\hline Heat Transfer & Enabled \\
\hline $\begin{array}{l}\text { Species } \\
\text { Transport }\end{array}$ & $\begin{array}{l}\text { Enabled, volumetric-include with wall } \\
\text { reaction and mass deposition source, } \\
\text { Diffusion, and diffusion source enabled }\end{array}$ \\
\hline $\begin{array}{l}\text { Pressure- } \\
\text { Velocity } \\
\text { Coupling }\end{array}$ & Simple \\
\hline
\end{tabular}

Table 3 depicts methods utilized in current research and other special techniques used for solution.

Table 3 Spatial discretization selection

\begin{tabular}{ll}
\hline Spatial discretization & Option \\
\hline Gradient & Least Squares Based \\
\hline Pressure & Standard \\
\hline Momentum & Second-Order Upwind \\
\hline Turbulent Kinetic Energy & Second-Order Upwind \\
\hline Turbulent Dissipation Rate & Second-Order Upwind \\
\hline Species $\left(\mathbf{C a S O}_{\mathbf{4}}\right)$ & Second-Order Upwind \\
\hline Energy & Second-Order Upwind \\
\hline
\end{tabular}

Under relaxation factors are set as the default while simulating the plate heat exchanger fouling in $2 \mathrm{D}$ viz., pressure: 0.3 , density: 1 , body forces: 1 , momentum: 0.7, turbulent kinetic energy: 0.8 , turbulent dissipations rate: 0.8 , turbulent viscosity: 1 , species $\mathrm{CaSO}_{4}: 1$, energy: 1 .

The equations activated for this simulation were of flow, turbulence, and $\mathrm{CaSO}_{4}$ The simulation was run taking time step of $3600 \mathrm{~s}$, no. of time steps $=1000$, no. of iterations per time step $=20$. After about 7800 iterations, the solution was converged. The converged solution for all five cases had residuals below 1E-06. Defining reaction for mixture species in species transport model; Mixture $-\mathrm{CaSO}_{4}$, no. of reactions $=1$, reaction type- wall surface. No. of reactants $=2\left(\mathrm{CaSO}_{4}\right.$ and $\left.\mathrm{H}_{2} \mathrm{O}\right)$, No. of products $=$ $1\left(\mathrm{CaSO}_{4} \cdot 2 \mathrm{H}_{2} \mathrm{O}\right)$.

Stoichiometric-coefficient: $\mathrm{CaSO}_{4}=1, \mathrm{H}_{2} \mathrm{O}=2$, $\mathrm{CaSO}_{4} \cdot 2 \mathrm{H}_{2} \mathrm{O}=1$, and activation energy $=3.71 \times$ $10^{7} \mathrm{j} / \mathrm{kgmol}$.

\section{Results and discussions}

This paper mainly focused on a simulation study investigating the fouling formation in a plate heat exchanger by neglecting the effects of corrugation. A single plate (considered for present analysis) of the plate heat exchanger has been heated electrically. The fluid is a salt solution, (i.e., $\mathrm{CaSO}_{4}$ in water), flowing 
over the heated plate. The geometry of plate heat exchanger and the other boundary conditions for the present investigation has been taken the same as was taken in the experimental investigations (results of which taken for validation), with a modification that the width is assumed negligible specifically for the present 2D problem. It includes a cross-section having a thickness of $60 \mathrm{~mm}$ at the inlet and a crosssection of $31 \mathrm{~mm}$ (annular space for flowing fluid) at the outlet. The outlet cross-section is reduced equal to the thickness of the plate $(29 \mathrm{~mm})$. The heat exchanger has a length of $700 \mathrm{~mm}$ subjected to a constant heat flux at the dividing plate over a span of $255 \mathrm{~mm}$. The salt solution is subjected to heat, due to which $\mathrm{CaSO}_{4}$ crystallizes to get deposited on a heated surface because of its decreasing solubility with rising temperature. Further, the flow is considered $2 \mathrm{D}$, and the process is studied by the fluid's varying inlet velocity and heat flux. Thus, the proposed approach mainly emphasizes the significance of fouling and its consequences. The present problem discusses the simulation results of fouling analysis of the plate heat exchanger in the $2 \mathrm{D}$ domain. For analysis, an aqueous solution of $\mathrm{CaSO}_{4}$ was taken at the inlet of the domain. Then a constant heat flux at the dividing plate was given, along which solution was flowing. As the solution was heating, $\mathrm{CaSO}_{4}$ solubility decreased, crystallizing as gypsum along the plate surface. The deposited gypsum mass depends upon the heat flux and inlet velocity. That deposition would have a varying thickness and resistance to heat flux called fouling thickness and fouling resistance, respectively, depending upon the heat flux given and inlet velocity. Fouling tests were carried out with a fixed $\mathrm{CaSO}_{4}$ concentration $\left(\mathrm{C}_{\mathrm{f}}=\right.$ $2.42 \mathrm{~g} / \mathrm{l})$ and various mass flow rates and heat fluxes. For validation purposes, the observed and numerically computed values of fouling resistance are plotted against time at a given flow velocity of $0.2 \mathrm{~m} / \mathrm{s}$ and a heat flux $53 \mathrm{~kW}$, as shown in Figure 8 . The different related parameters that affect the fouling of gypsum on plate surfaces are discussed. For this, a simulation on fluent 6.3 was done, and various simulation results were analyzed to reach some conclusions. For that, a step-by-step procedure was adopted and the obtained results are discussed under different headings in the following subsections:

\subsection{Validation}

First of all, a case was considered that could be used as validation for the simulated results obtained. For that, the case was considered when heat flux was $53 \mathrm{~kW} / \mathrm{m}^{2}$ and velocity was $0.2 \mathrm{~m} / \mathrm{s}$. The included results compared the simulated data obtained from simulation analysis with the experimental data as shown by Watkinson and Wilson in [14]. Figure 8 and Figure 9 show that fouling resistance plotted against the time follows the similar pattern when plotted for the results obtained from simulations and the experiments. Hence it can be concluded that the agreement between simulated and experimental results is satisfactory. Therefore the results obtained by the simulation analysis can be assumed to have predicted the fouling phenomenon with sufficient accuracy.

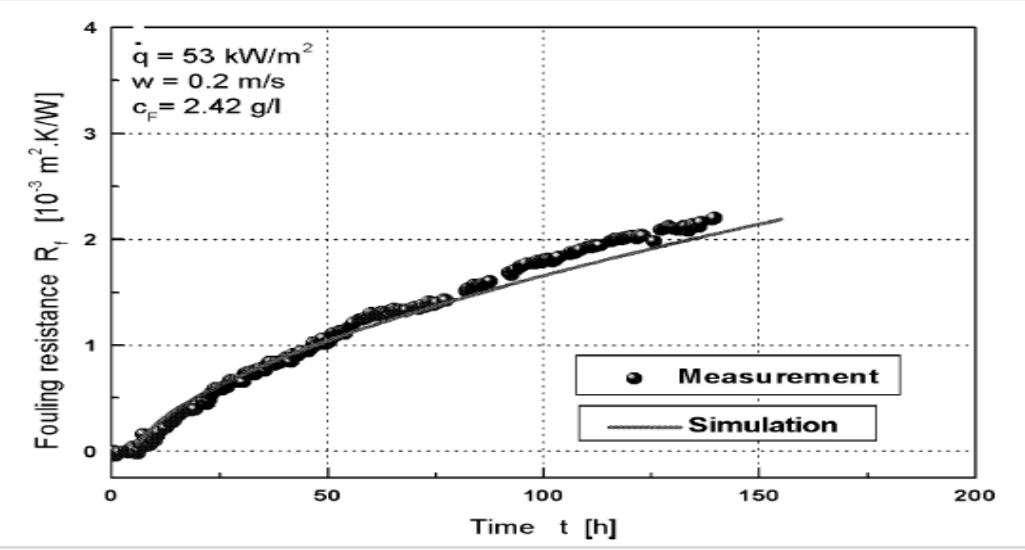

Figure 8 Measurement and simulation comparison 


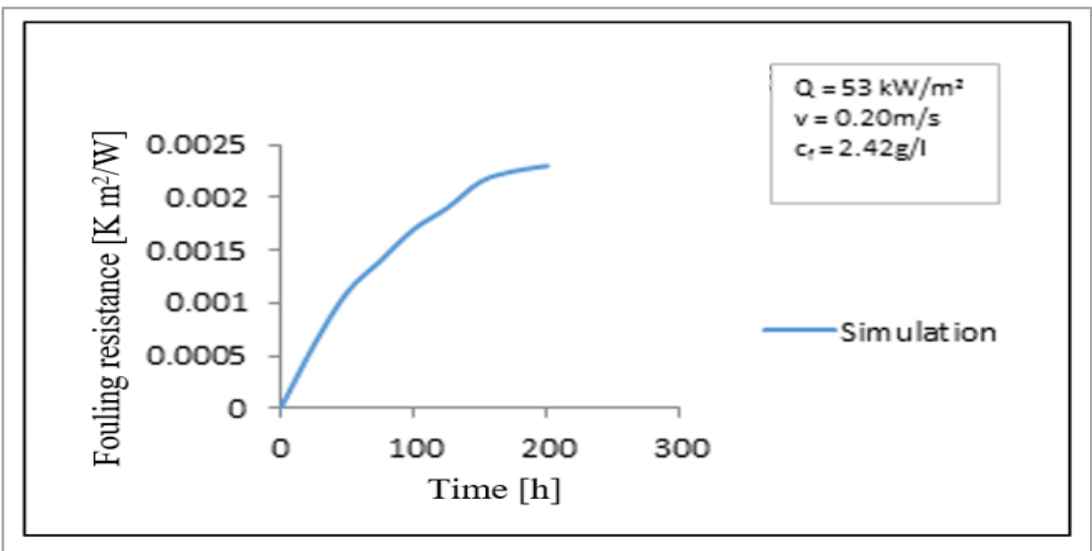

Figure 9 Validation of present model comparison with the actual result

\subsection{Contours}

To have a closer look at the fouling phenomenon, the important contours obtained from the simulation analysis are presented below. Figure 10 shows the velocity contours obtained from the post-processing of the above analysis. It can be seen that velocity increase along the length due to a decrease in crosssection because of the plate itself and the deposition on the heated walls.

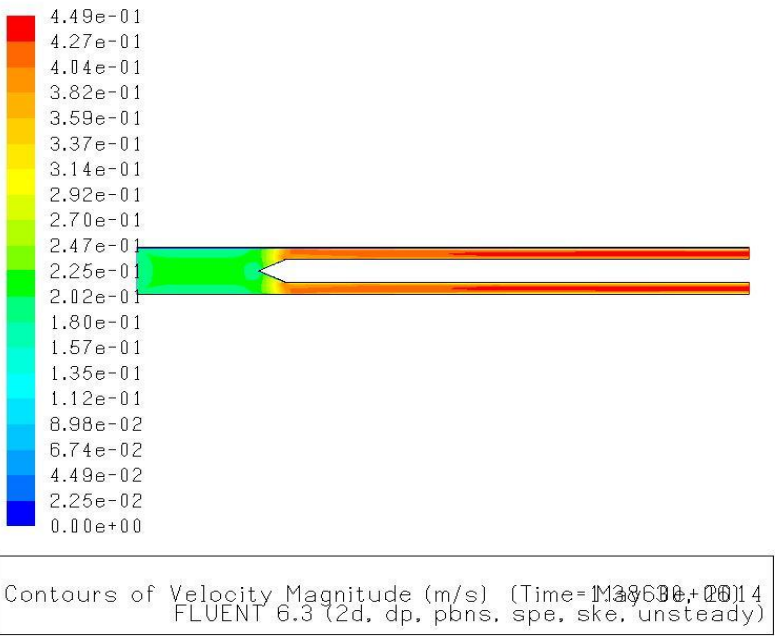

Figure 10 Velocity contours [after $385 \mathrm{~h}] \mathrm{v}=0.2 \mathrm{~m} / \mathrm{s}, \dot{\boldsymbol{Q}}$ $=53 \mathrm{~kW}$

Figure 11 to Figure 12 show that mass deposition occurs only at the heated site of the plate because the surface reaction occurs at that site and the maximum deposition rate is $8.06 \mathrm{e}-06 \mathrm{~kg} / \mathrm{m}^{2} \mathrm{~s}$. The velocity of the solution increases due to a decrease in crosssection at the heated site.
Figure 13 shows that the mass fraction of $\mathrm{CaSO}_{4}$ is maximum at the inlet of the solution and it decreases as the solution passes over heated plate. This is due to the solubility dependence of $\mathrm{CaSO}_{4}$ on temperature. The $\mathrm{CaSO}_{4}$ comes out of solution and deposited at the heated surface as $\mathrm{CaSO}_{4} \cdot 2 \mathrm{H}_{2} \mathrm{O}$ i.e., gypsum as solid material results in a mass fraction in solution decreases.

Minimum value $=0.002418696$ and maximum value $=0.00242$.

From Figure 14 it can be seen that the mass fraction of water increases from inlet to outlet due to a decrease in $\mathrm{CaSO}_{4}$ mass fraction in the solution having a minimum value of 0.9975798 and a maximum value of 0.9975813 .

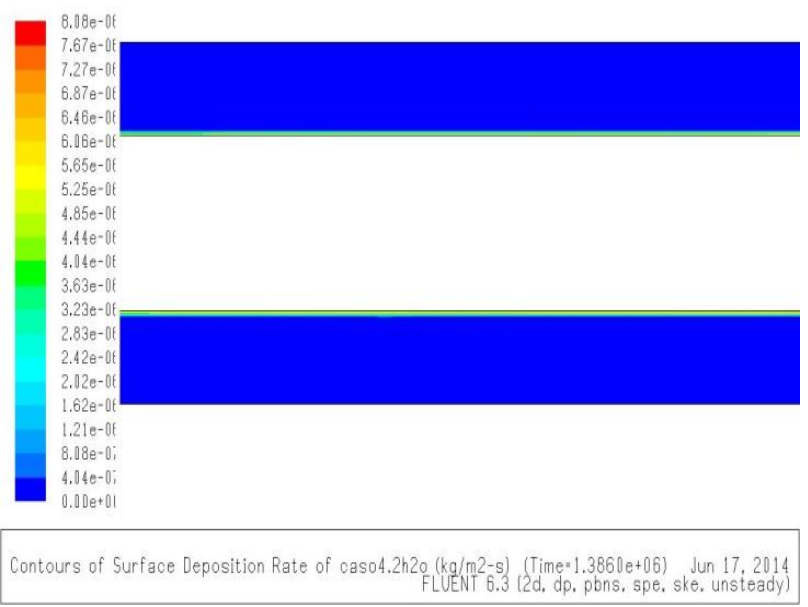

Figure 11 Mass deposition rate of gypsum on heated part of plate [after $385 \mathrm{~h}$ ] v $=0.2 \mathrm{~m} / \mathrm{s}, \dot{\boldsymbol{Q}}=53 \mathrm{~kW}$ 


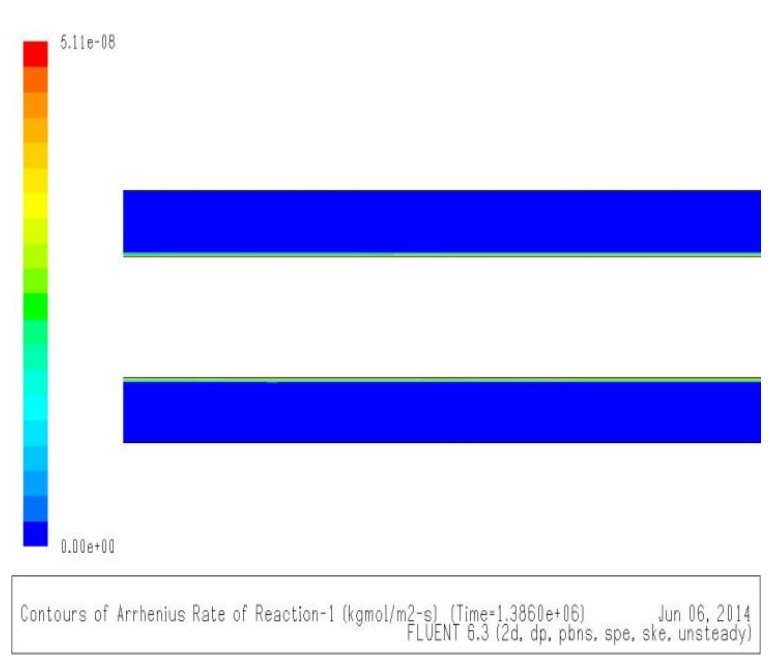

Figure 12 Contour of Arrhenius rate of reaction [after $385 \mathrm{~h}$ ] v $=0.2 \mathrm{~m} / \mathrm{s}, \dot{\boldsymbol{Q}}=53 \mathrm{~kW}$

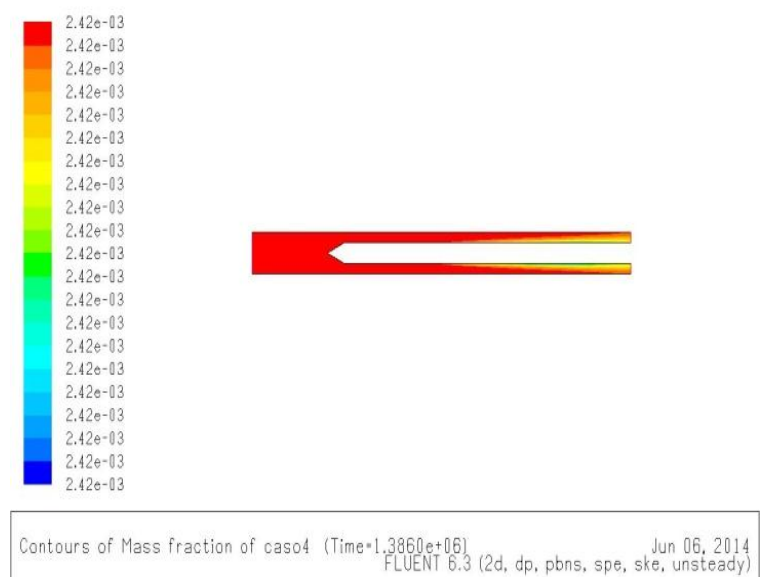

Figure 13 contours of $\mathrm{CaSO}_{4}$ mass fraction [after $385 \mathrm{~h}] \mathrm{v}=0.2 \mathrm{~m} / \mathrm{s}, \dot{\boldsymbol{Q}}=53 \mathrm{~kW}$

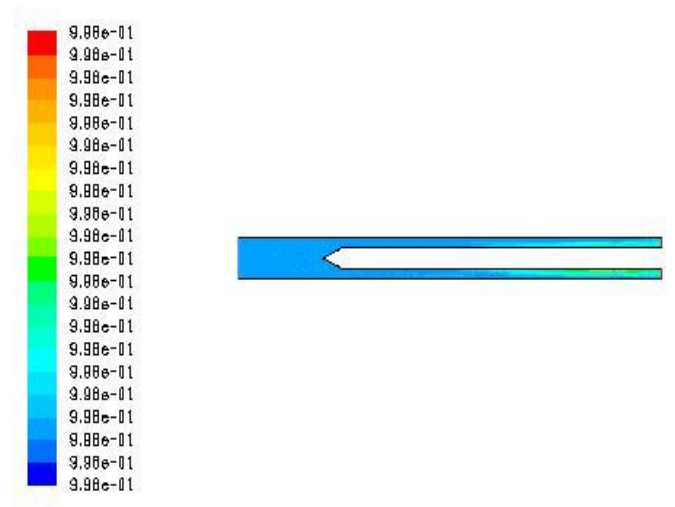

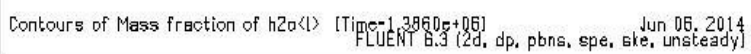

Figure 14 contours of water mass fraction [after $385 \mathrm{~h}] \mathrm{v}=0.2 \mathrm{~m} / \mathrm{s}, \dot{\boldsymbol{Q}}=53 \mathrm{~kW}$

\subsection{Fouling as a function of time and space}

The fouling phenomenon varies with time and also with space i.e. it is a case of transient and space. Therefore, the simulation results of fouling include both time and space dependencies.

\section{Fouling as Function of Time}

Here we consider a line with coordinates $\mathrm{A}(0.35,0.0445)$ and $\mathrm{B}(0.35,0.060)$ in the domain itself and then analyze the fouling phenomenon at this line concerning time only.

The steps followed were;

1. Analyzed and calculated mass deposition rate variation of gypsum at this line with changing time.

2. The deposition rate was used to calculate the total mass deposition at this line using relation (Equation 22).

$m_{t+\Delta t}=m_{t}+\dot{m} \times \Delta \mathrm{t}$

3. Now density was assumed fouling thickness was calculated as (Equation 23).

$\mathrm{x}=\frac{m_{t+\Delta t}}{\rho}$

Again a constant thermal conductivity of gypsum $\lambda=$ $0.5 \mathrm{~W} / \mathrm{m}-\mathrm{K}$ was assumed and the fouling resistance i.e. resistance to heat transfer due to gypsum deposition was calculated (Equation 24).

$R_{f}=\frac{x}{\lambda}$

Simulation results for the same heat and different inlet velocity can be elaborated as:

The simulation results were obtained graphically as fouling thickness and fouling resistance $\mathrm{v} / \mathrm{s}$ time in hours as shown in the following Figures.

\section{Fouling thickness;}

Figure 15 shows that the fouling thickness increase exponentially at a first and passing time leads to an almost constant thickness of gypsum deposition. This happens due to the reason that initially as the temperature increases because of heat transfer the solubility of gypsum decreases and it starts depositing on the heated walls but as time passes and also the heat transfer decreases due to already deposited material the thickness will attain a maximum value. As the inlet velocity decreases the thickness of deposition of gypsum increases i.e. fouling thickness depends upon the inlet velocity. Because with an increase in inlet velocity the turbulence in the flow increases which leads to detachment of deposited material which further results in a decrease of fouling thickness. 


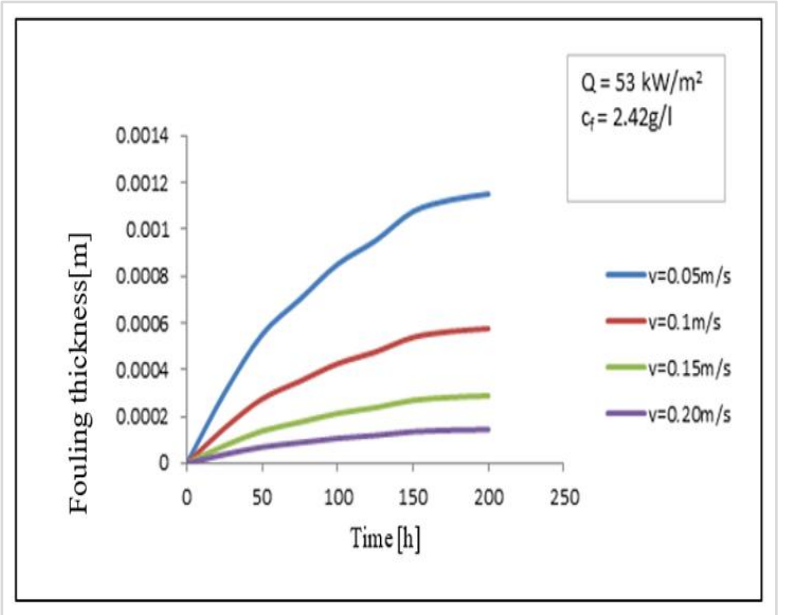

Figure 15 Fouling thickness curves for different velocity inlet and $\dot{\boldsymbol{Q}}=53 \mathrm{~kW}$

\section{Fouling Resistance;}

Figure 16 explains the fouling resistance variation with time and inlet velocity and shows that the resistance to heat transfer i.e. fouling resistance increases with time exponentially and after passes of time it tends to be constant. It happens due to an increase in fouling thickness and hence follows almost the same trend as was followed by fouling thickness.

Fouling resistance also depends upon inlet velocity and its slope increase with decreasing inlet velocity magnitude.

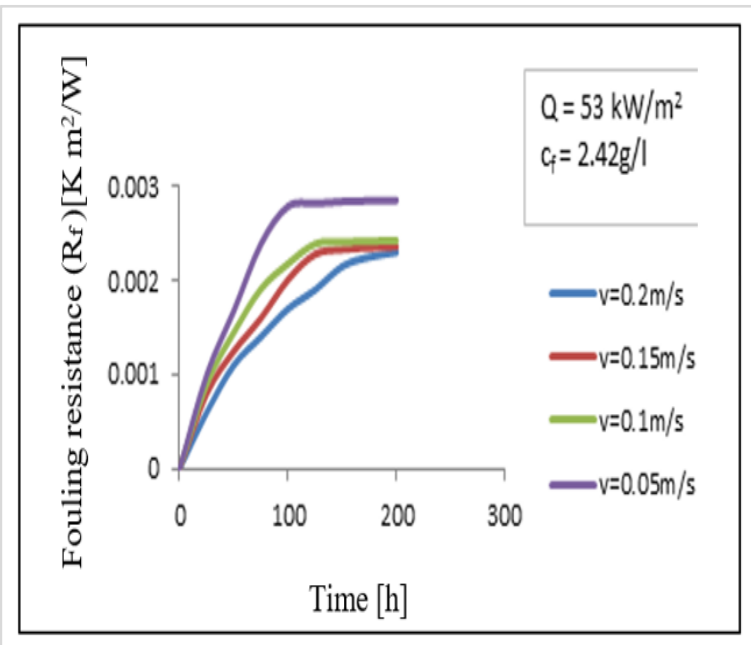

Figure 16 Fouling resistance curves for different velocity inlet and $\dot{\boldsymbol{Q}}=53 \mathrm{~kW}$
Simulation results for the same inlet velocity and different heat flux:

\section{Fouling thickness;}

Fouling thickness increase exponentially at first and passing time leads to an almost constant thickness of gypsum deposition as represented in Figure 17. Again this happens due to the reason that initially as the temperature increases because of heat transfer the solubility of gypsum decreases and it starts depositing on the heated walls but as time passes and also the heat transfer decreases due to resistance offered by already deposited material the thickness will attain a maximum value.

With increasing, heat flux slope of fouling thickness becomes steeper i.e. fouling thickness increases rapidly when heat input increases. The reason behind this is the increase in surface reaction rate at the heated site of the plate.

In case of a decrease in heat flux input, fouling thickness decreases. Again this is because of reaction rate decrement with less heat input.

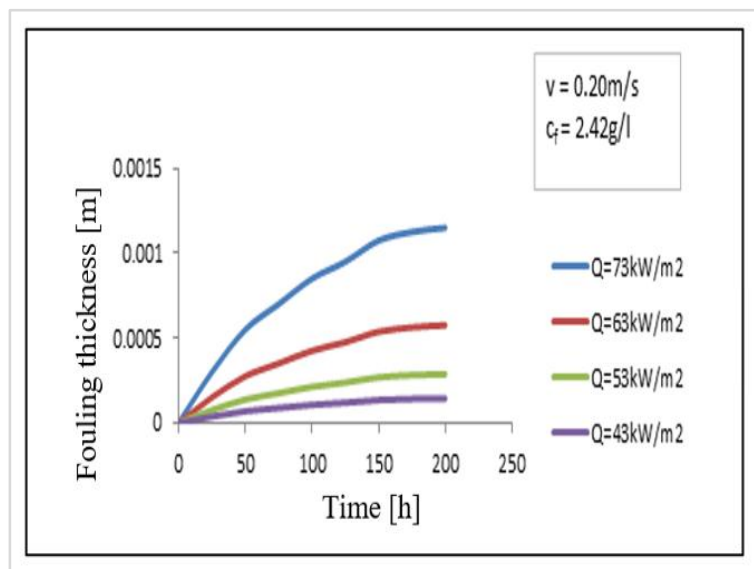

Figure 17 Fouling thickness curves for different $\dot{\boldsymbol{Q}}$ and $\mathrm{v}=0.2 \mathrm{~m} / \mathrm{s}$

\section{Fouling resistance;}

Resistance to heat transfer i.e. fouling resistance increases with time exponentially and after passing of time it tends to be constant as shown in Figure 18. With increasing, heat flux slope of fouling resistance becomes steeper i.e. fouling resistance increases rapidly when heat input increases. The reason behind this is the increase in surface reaction rate at the heated site of the plate and vice-versa. 


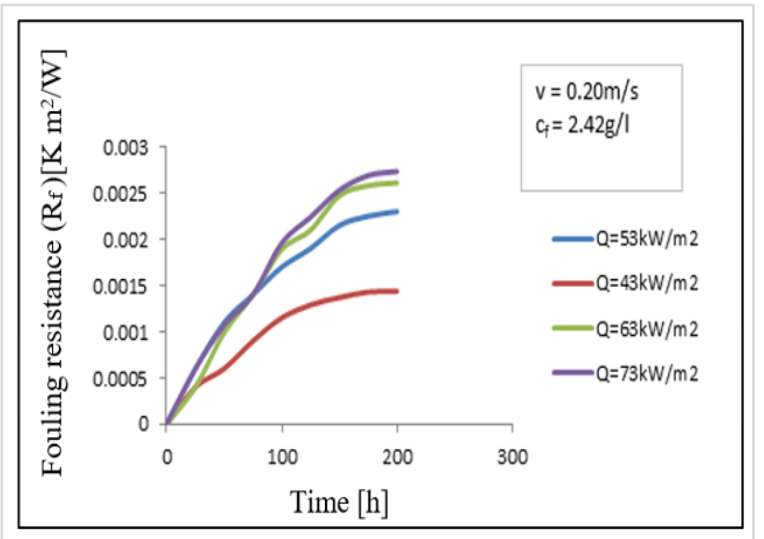

Figure 18 Fouling resistance curves for different $\dot{\boldsymbol{Q}}$ and $\mathrm{v}=0.2 \mathrm{~m} / \mathrm{s}$

\section{Fouling as Function of Space}

Fouling may be assumed to become a steady phenomenon with time say after $100 \mathrm{~h}$ in which the fouling thickness attains maximum value. In that situation, its dependency on location can be understood by the following simulation results obtained.

\section{Mass deposition rate at the heated plate along its length:}

Different inlet velocities will give different deposition rates along the length of the heated portion of the plate as shown in Figure 19 obtained as simulation results. It can be seen that for a constant heat flux along the length of the plate the deposition rate increases along the length. It is due to the rise of temperature along the length which leads to $\mathrm{CaSO}_{4}$ solubility decrement in the solution. Also with the rise of inlet velocity the mass deposition rate decreases. Moreover, the less magnitude of velocity at the inlet results in a steeper curve.

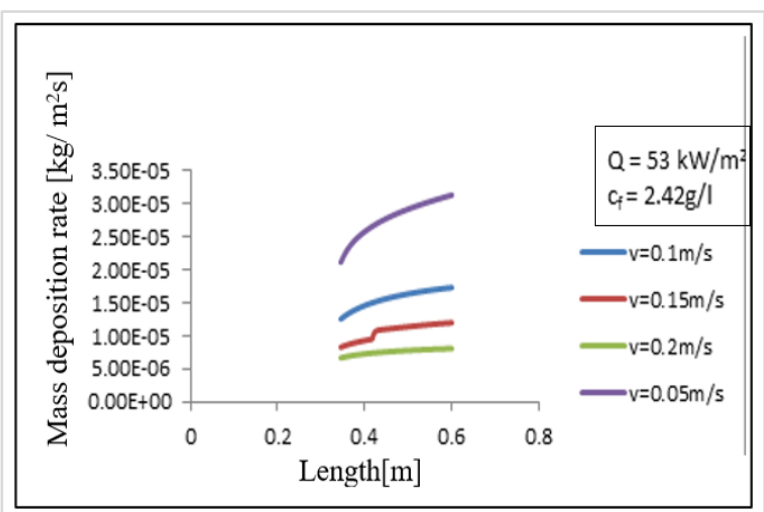

Figure 19 Mass deposition rate along the length of the heated plate
Surface heat transfer coefficient variation at the heated plate along its length;

The surface heat transfer coefficient is a function of velocity and fouling thickness. Along with the length fouling thickness and hence fouling resistance increases which results in a decrease in surface heat transfer coefficient. Further heat transfer coefficient increases with an increase in the magnitude of inlet velocity as a result of an increase in $\mathrm{Re}$ and decreasing fouling thickness as shown in Figure 20.

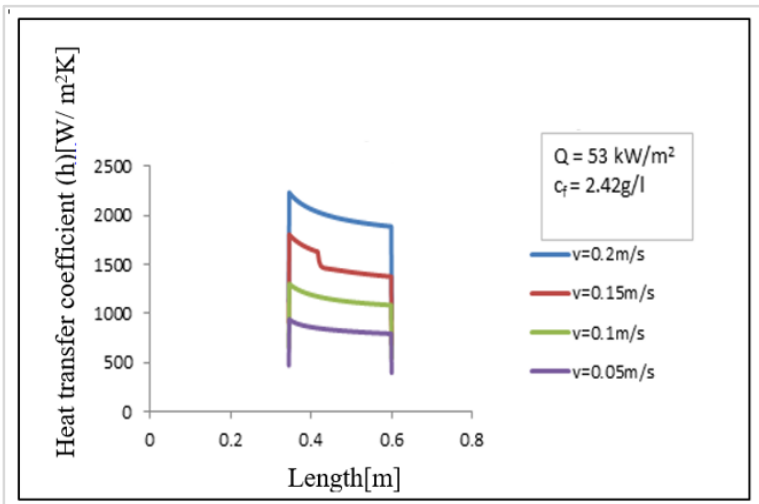

Figure 20 Surface heat transfer coefficient variation along with a heated plate

\subsection{Limitations}

The only concern with this numerical model is its over-prediction of the experimentally determined fouling rates. However, it is hard to make a comprehensive analysis to explain the reasons for this over-prediction without including a roughness delay period, which is present in the experimental results. The thermal resistance of the growing deposit eventually countered the advantage that the interface roughness has on promoting heat transfer. This inclusion of roughness provided further insight into the interaction of the developing deposit and the local behavior of the operating parameters. At a local level, the occurrence of roughness considerably increased the buildup of the species adjacent to the wall and, at the same time, caused a significant drop in the local temperature at the interface.

Hence, fouling analysis, including fouling layer thickness, fouling resistance, mass deposition rate, and so on, is only considered under certain operating conditions, primarily heat transfer rate, inlet velocity, and concentration. Other factors, such as wall roughness and cross-section of flow passages, may significantly impact fouling deposition in heat exchangers and should be considered for more accurate results. 
A complete list of abbreviations is shown in Appendix I.

\section{Conclusion and future work}

This proposed work demonstrated the usefulness of adopting the CFD method in examining heat exchanger fouling and associated phenomena. The objective of the work is to develop a simulating model using CFD that details the fouling phenomenon common to crystalline streams. Once completed, the model will assist in understanding fouling and the intricate interactions of essential operation of parameters on a local scale. Model components are developed and assessed using a progressive stage-wise strategy.

The results imply that the distribution of velocity and residence time affects the precipitation process's behavior. The distribution of velocity and residence time forms an aqueous species concentration gradient close to the wall. These generated concentration gradients may lead species to migrate towards the transfer surface and encourage crystallization deposition at the surface. The CFD approach's ability to accurately model the precipitation process has aided in a better understanding of the velocity, temperature, and concentration gradients influencing fouling processes.

The numerical solutions for the crystallization flux are validated with corresponding experimental fouling resistance distributions to provide an insight into factors determining the likelihood of the fouling mechanisms. It revealed that the deposited particles are generated within the boundary layer and not the bulk, emphasizing the importance of assessing the interactions within the boundary layer. The detail used in making these assessments are also applied to the local operating parameters and assisted in elucidating the most influential parameter on a local scale.

The impact that deposit growth has in terms of fouling is observed by calculating the fouling resistance and monitoring its temporal variation. The resulting fouling curves are used to estimate numerical values for the fouling rate. Validation with experimental work confirmed the successful reproduction of the transient crystallization fouling. It also demonstrated the CFD's ability to predict the fouling rates satisfactorily. Hence, the key objective of creating a predictive fouling model is successfully achieved.
The predicted fouling rates analysis indicates that the fouling phenomenon is greatly affected by velocity magnitude at the inlet and temperature change due to constant heat flux at the plate. Completing various stages continually provides evidence that CFD is an excellent tool in modeling the intricate fouling processes. The application of the CFD method has proven to be beneficial in investigating various aspects of fouling associated with crystalline streams. The ability of the resulting CFD model to predict the temporal variation of fouling resistance proves the numerical method is an effective alternative to the traditional experimental approach.

The numerical modeling of the fouling phenomenon presented in this work is specific to crystallization fouling. In the case of any other type of fouling, which may be required to study using simulation, the modeling needs to be modified depending on the fouling type considered. Hence, by understanding the present modeling process of crystallization fouling and findings so obtained, the study can be extended to the analysis of different types of fouling found in various practical applications.

Fouling analysis, including fouling layer thickness, fouling resistance, mass deposition rate, and so on, are only considered under certain operating conditions, primarily heat transfer rate, inlet velocity, and concentration. Other factors, such as wall roughness and cross-section of flow passages, may significantly impact fouling deposition in heat exchangers and should be considered for more accurate results. So a separate simulation analysis can be carried out by considering the mentioned factors affecting fouling mainly at local levels.

\section{Acknowledgment}

None.

\section{Conflicts of interest}

The authors have no conflicts of interest to declare.

\section{Authors contribution statement}

Amit Kumar: Conceptualization, investigation, data curation, writing - original draft, writing - review and editing, analysis and interpretation of results. Sandeep Yadav: Data collection, conceptualization, draft manuscript preparation. Dilbag Singh Mondloe: Study conception, investigation on challenges and writing review and editing. Vinayak Barewar: Study conception, writing - review and editing, draft manuscript preparation. Yogender Kumar: Study conception, draft manuscript preparation Vinay Pandit: Study conception, draft manuscript preparation. 


\section{References}

[1] Taborek J. Fouling: the major unsolved problem in heat transfer. Chemical Engineering Progress. 1972; 68:59-67.

[2] Mukherjee R. Conquer heat exchanger fouling. Hydrocarbon Processing. 1996; 75(1).

[3] Karabelas AJ. Scale formation in tubular heat exchangers-research priorities. International Journal of Thermal Sciences. 2002; 41(7):682-92.

[4] Brahim F, Augustin W, Bohnet M. Numerical simulation of the fouling process. International Journal of Thermal Sciences. 2003; 42(3):323-34.

[5] Khan MS, Budair MO, Zubair SM. A parametric study of $\mathrm{CaCO}_{3}$ scaling in AISI 316 stainless steel tubes. Heat and Mass Transfer. 2001; 38(1):115-21.

[6] Langelier WF, Caldwell DH, Lawrence WB, Spaulding CH. Scale control in sea water distillation equipment-contact stabilization. Industrial \& Engineering Chemistry. 1950; 42(1):126-30.

[7] Xu Z, Han Z, Wang J, Li Y. Numerical simulation of $\mathrm{CaSO}_{4}$ crystallization fouling in a rectangular channel with vortex generators. International Communications in Heat and Mass Transfer. 2019; 101:42-50.

[8] Lv Y, Lu K, Ren Y. Composite crystallization fouling characteristics of normal solubility salt in double-pipe heat exchanger. International Journal of Heat and Mass Transfer. 2020.

[9] Kern D. A theoretical analysis of thermal surface fouling. Journal of Chemical Engineering of Japan. 1959; 4:258-62.

[10] Bornstein L. Numerical data and functional relationships in science and technology. Magnetic and Another Properties of Oxides and Related Compounds. Pt. A Garnets and Perovscites. 1978.

[11] Bott TR. Fouling of heat exchangers. Elsevier; 1995.

[12] Mullin JW. Crystallization. 2nd Edition. Crystal Research and Technology Butterworths, London, 1972.

[13] Müller-steinhagen $\mathrm{H}$, Zhao Q. Investigation of low fouling surface alloys made by ion implantation technology. Chemical Engineering Science. 1997; 52(19):3321-32.

[14] Watkinson AP, Wilson DI. Chemical reaction fouling: a review. Experimental Thermal and Fluid Science. 1997; 14(4):361-74.

[15] Hasson D. Precipitation fouling: fouling of heat transfer equipment. Invited Paper, Haifa. 1981:527-68.

[16] Bohnet M. Fouling of heat transfer surfaces. Chemical Engineering \& Technology. 1987; 10(1):113-25.

[17] Song KS, Lim J, Yun S, Kim D, Kim Y. Composite fouling characteristics of $\mathrm{CaCO}_{3}$ and $\mathrm{CaSO}_{4}$ in plate heat exchangers at various operating and geometric conditions. International Journal of Heat and Mass Transfer. 2019; 136:555-62.

[18] Al-ahmad M, Aleem FA. Scale formation and fouling problems and their predicted reflection on the performance of desalination plants in Saudi Arabia. Desalination. 1994; 96(1-3):409-19.
[19] Ma Q, Tipping RH, Boulet C. Irreducible correlation functions of the $\mathrm{S}^{\wedge}$ matrix in the coordinate representation: application in calculating Lorentzian half-widths and shifts. The Journal of Chemical Physics. 2006; 124(1).

[20] Isogai S, Nakamura M, Inokuchi H, Kimura H, Koga Y. Measurement and modeling for the mitigation of organic crystallization fouling. Heat Exchanger Fouling and Cleaning: Fundamentals and Applications. 2003.

[21] Reitzer BJ. Rate of scale formation in tubular heat exchangers, mathematical analysis of factors influencing rate of decline of over-all heat transfer coefficients. Industrial \& Engineering Chemistry Process Design and Development. 1964; 3(4):345-8.

[22] Inokuchi H, Nakamura M, Koga Y. Study of an organic crystallization fouling problem. Proceedings of 7 th international conference on heat exchanger fouling and cleaning - challenges and opportunities. 2007 (pp.172-4).

[23] Pääkkönen TM, Riihimäki M, Simonson CJ, Muurinen E, Keiski RL. Modeling $\mathrm{CaCO}_{3}$ crystallization fouling on a heat exchanger surfacedefinition of fouling layer properties and model parameters. International Journal of Heat and Mass Transfer. 2015; 83:84-98.

[24] Pääkkönen TM, Riihimäki M, Simonson CJ, Muurinen E, Keiski RL. Crystallization fouling of $\mathrm{CaCO}_{3}$-analysis of experimental thermal resistance and its uncertainty. International Journal of Heat and Mass Transfer. 2012; 55(23-24):6927-37.

[25] Epstein N. Thinking about heat transfer fouling: a $5 \times$ 5 matrix. Heat Transfer Engineering. 1983; 4(1):4356.

[26] Pääkkönen TM, Ojaniemi U, Pättikangas T, Manninen M, Muurinen E, Keiski RL, et al. CFD modelling of $\mathrm{CaCO}_{3}$ crystallization fouling on heat transfer surfaces. International Journal of Heat and Mass Transfer. 2016; 97:618-30.

[27] Nikoo AH, Malayeri MR, Al-janabi A. Fouling propensity of modified heat transfer surfaces. Heat Transfer Engineering. 2020; 41(11):919-33.

[28] Sundar S, Rajagopal MC, Zhao H, Kuntumalla G, Meng Y, Chang HC, et al. Fouling modeling and prediction approach for heat exchangers using deep learning. International Journal of Heat and Mass Transfer. 2020.

[29] Dong L, Crittenden BD, Yang M. Fouling characteristics of water-CaSO4 solution under surface crystallization and bulk precipitation. International Journal of Heat and Mass Transfer. 2021.

[30] Xu Z, Zhao Y, Han Z, Wang J. Numerical simulation of calcium sulfate $\left(\mathrm{CaSO}_{4}\right)$ fouling in the plate heat exchanger. Heat and Mass Transfer. 2018; 54(7):186777.

[31] Schlüter F, Augustin W, Scholl S. Application of experimental data to model local fouling resistances. Heat and Mass Transfer. 2022; 58(1):29-40. 


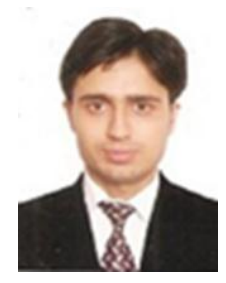

Amit Kumar has received his B.Tech. in Mechanical Engineering from UIET MDU Rohtak (Haryana) and M. Tech in Mechanical Engineering from Dr. BR Ambedkar NIT Jalandhar (Punjab). He has served as Assistant Professor in SRM University Delhi NCR, Sonipat (Haryana) during 2015-16 and from 2016 onwards serving in IGEC Sagar (M.P). His areas of interest are Cold Spray Additive manufacturing, CFD, and Renewable Energy. He has a total of seven years of experience in Mechanical Engineering.

Email: amitkumar.igec@gmail.com

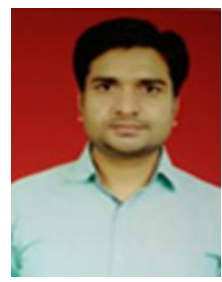

Sandeep Yadav has received his B.Tech. in Mechanical Engineering from RTU Kota (Raj.), M. Tech in Mechanical Engineering from Dr. BR Ambedkar NIT Jalandhar (Punjab), and is currently pursuing a Ph.D. from MBM Engineering College, JNV University, Jodhpur (Raj.) He has served as Assistant Professor in JECRC, Jaipur (Raj.) during 2014-17 and from 2017 onwards serving in MBM Engineering College, JNV University, Jodhpur (Raj.). His areas of interest are Alternative Fuels in IC Engine, CFD, and Renewable Energy. He has a total of seven years of experience in Mechanical Engineering.

Email: ydv.sndp3004@gmail.com

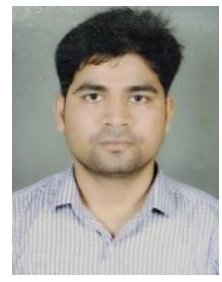

Dilbag Singh Mondloe has received his B.E. in Mechanical Engineering from GEC Jagdalpur (C.G.), M. Tech in Heat Power Engineering from VNIT Nagpur (M.H.), and is currently pursuing a Ph.D. from CSVTU Bhilai (C.G.) $\mathrm{He}$ has served as Assistant Professor in ATMIYA University Rajkot (Gujarat) during 2014-16 and from 2016 onwards serving in GEC Jagdalpur (C.G.). He has published more than 15 research articles in an international journal. He has a total of seven years of experience in Mechanical Engineering.

Email: dsmondloe@gecjdp.ac.in

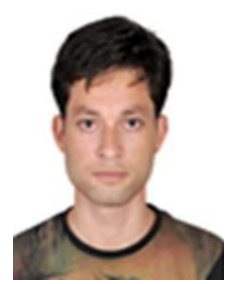

Vinayak Barewar has received his B.E. in Mechanical Engineering from UIT BU Bhopal (M.P.), M. Tech in Heat Power Engineering from VNIT Nagpur (M.H.). He has served as Assistant Professor in G.H. Raisoni college Nagpur M.H. during 2014-15 and from 2016 onwards serving in IGEC Sagar (M.P.). He has a total of six years of experience in Mechanical Engineering.

Email: vinayak.barewar055@gmail.com

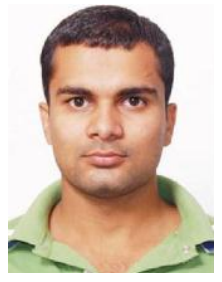

Yogender Kumar has received his B.Tech. in Mechanical Engineering from DCRUST Murthal (Haryana), M. Tech in Thermal Engineering from NIT Kurukshetra (Haryana). He has been working as Assistant Professor at Indira Gandhi Engineering College, Sagar (M.P.) since 2016. He has a total of five years of experience in Mechanical Engineering. Email: ykbhardwaj1990@gmail.com

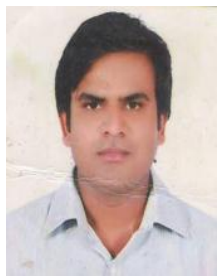

Vinay Pandit completed his bachelor's degree in Mechanical engineering from IET DAVV(M.P.) after that he completed his M.Tech degree from SVNIT Surat (Gujrat). He worked as Assistant Professor in SDBCT Indore ( M.P.) during the year $2014-2015$ and IPS Academy Indore( M.P) during the year 2015- 2016. While working here, he presented his research work in the $31^{\text {st }}$ M.P. Young Scientist Congress Bhopal, (M.P.). Presently he is working as Assistant Professor in IGEC Sagar, (M.P.). He has more than 7 years of teaching experience in mechanical engineering and has guided many projects work during this period.

Email: vinaymech29@yahoo.co.in

\begin{tabular}{llll}
\multicolumn{2}{l}{ Appendix 1 } \\
\hline S. No. & Abbreviation & Descriptions \\
\hline 1 & 2D & Two Dimensional & \\
\hline 2 & $3 \mathrm{D}$ & Three Dimensional & \\
\hline 3 & $\mathrm{CaCO}_{3}$ & Calcium Carbonate & \\
\hline 4 & $\mathrm{CaSO}_{4}$ & Calcium Sulfate & \\
\hline 5 & $\mathrm{CFD}$ & Computational Fluid Dynamics & \\
\hline 6 & DLVO & $\begin{array}{l}\text { Derjaguin, Landau, Verwey and } \\
\text { Overbeek }\end{array}$ \\
\hline 7 & FPI & Fouling Propensity Indicator & \\
\hline 8 & PDEs & Partial Differential Equations & \\
\hline 9 & PIV & Particle Image Velocimetry \\
\hline 10 & Re & Reynolds Number \\
\hline 11 & RNG & Re-Normalization Group \\
\hline 12 & VGs & Vortex Generators \\
\hline
\end{tabular}

